\title{
Factors Governing Sustainable Groundwater Pumping near a River
}

Yingqi Zhang ${ }^{1}$, Susan Hubbard and Stefan Finsterle

\author{
Earth Sciences Division \\ Lawrence Berkeley National Laboratory \\ University of California \\ 1 Cyclotron Road, MS 90-1116, \\ Berkeley, California 94720-8126 \\ Tel 510-495-2983 \\ Fax 510-486-5686 \\ Email yqzhang@lbl.gov
}




\section{Abstract}

The objective of this paper is to provide new insights into processes affecting riverbank filtration (RBF). We consider a system with an inflatable dam installed for enhancing water production from downstream collector wells. Using a numerical model, we investigate the impact of groundwater pumping and dam operation on the hydrodynamics in the aquifer and water production. We focus our study on two processes that potentially limit water production of an RBF system: the development of an unsaturated zone and riverbed clogging. We quantify river clogging by calibrating a time-dependent riverbed permeability function based on knowledge of pumping rate, river stage, and temperature. The dynamics of the estimated riverbed permeability reflects clogging and scouring mechanisms. Our results indicate that (1) riverbed permeability is the dominant factor affecting infiltration needed for sustainable RBF production; (2) dam operation can influence pumping efficiency and prevent the development of an unsaturated zone beneath the riverbed only under conditions of sufficient riverbed permeability; (3) slow river velocity, caused by dam raising during summer months, may lead to sedimentation and deposition of fine-grained material within the riverbed, which may clog the riverbed, limiting recharge to the collector wells and contributing to the development of an unsaturated zone beneath the riverbed; and (4) higher river flow velocities, caused by dam lowering during winter storms, scour the riverbed an thus increase its permeability. These insights can be used as the basis for developing sustainable water management of a RBF system. 


\section{Introduction}

Groundwater pumping near rivers is utilized in water resources management to increase both water quantity and quality. River infiltration effectively recharges the groundwater extracted for drinking water purposes, and riverbank filtration (RBF) naturally improves the quality of through a variety of physiochemical and biological processes (Schubert, 2006b). Instead of constructing conventional water quality treatment facilities (e.g., coagulation/flocculation/sand filters, microfiltration), many municipalities have investigated the possibility of obtaining relatively clean potable water through the development of RBF systems (Fox and Durnford, 2003). Advantages of RBF relative to conventional treatment technologies include lower capital investments and operating costs due to lower energy requirements and reduced usage of chemicals. RBF is also used to pre-treat surface water of poor quality, reducing the cost of conventional water treatment and buffering fluctuations in the quality of the water entering a plant (Ray, et al., 2002).

Existing RBF systems are predominantly located along the riverbank of middle to lower reaches of rivers (Caldwell, 2006) and involve the use of collector wells that often extract from alluvial aquifers (Ray, et al., 2002). Both vertical and radial collector wells are used in RBF systems. In shallow aquifers, radial collector wells are preferable because they have large capacities (Caldwell, 2006). Some of these rivers are managed by a dam or a series of dams for river stage control.

Despite the advantages of using RBF systems for water resources management, optimizing riverbed filtration systems to provide sustainable, high-quality water presents a unique set of challenges (Schubert, 2002, 2006b). There are two common problems that can 
potentially affect the effectiveness of the filtration process: development of an unsaturated zone (Su et al., 2007) near the collector wells and riverbed clogging (Schubert, 2006a). The amount of water that infiltrates from the river to the aquifer will be affected by riverbed permeability, aquifer permeability, river stage, water table level, and pumping rate. An unsaturated zone may develop beneath the riverbed if the recharge rate from a losing river is less than the saturated hydraulic conductivity of the aquifer, or if the pumping rate is greater than the recharge rate. The development of an unsaturated zone reduces hydraulic conductivity and thus limits water production. Aeration caused by the development of an unsaturated region beneath the riverbed may also have a significant impact on the dynamics of hydrobiogeochemical processes, therefore also impacting the water quality (Fox and Durnford, 2003; Greskowiak, et al., 2005).

Riverbed clogging is also recognized as a specific problem of RBF systems (Goldschneider et al., 2007), indicated by observed declines in pumping capacity, and confirmed by pressure data, infiltration estimates, and sediment analyses (Hubbs, 2006b; Schubert, 2006a). Riverbed clogging is a highly dynamic process (Schubert, 2006a), usually caused by deposition or sedimentation of fine particles or biofilms accompanied by processes such as sorption, biotransformation, chemical oxidation and reduction, and ion exchange. Clogging rate and magnitude are governed by the river dynamics related to RBF operations as well as by (bio)geochemical reactions. For example, if clogging is primarily governed by physical processes, the clogging rate may be affected by the conditions in the river, such as flow velocity and suspended load, which is affected by the parent rock geology and human activity (Caldwell, 2006). The decreased hydraulic conductivity resulting from clogging may cause the development of an unsaturated zone beneath the riverbed, which in turn compresses the silt-laden riverbed and results in a further decrease in riverbed conductivity. Overpumping can also increase effective 
stress and lead to long-term soil compaction (Hubbs, 2006a). Biological and chemical clogging depend on the type and quantity of dissolved constituents and microbial ecology (Schälchli, 1992) as well as river temperature. Higher temperatures in the summer months promote biological and chemical clogging processes (Bouwer, 2002). Although acquisition and analysis of sediment and biofilm samples may provide direct information related to the clogging mechanism (Schälchli, 1992), there are many practical difficulties in retrieving undisturbed samples, relating sample information to depositional, geochemical or microbiology processes, obtaining riverbed permeabilities, and upscaling these property estimates to the scale useable in a regional river-aquifer model, as recognized by Cardenas and Zlotnik (2003), who emphasized the heterogeneity of riverbed heterogeneity.

Analytical approaches have been developed to investigate individual aspects associated with RBF systems. For example, Hunt (1999) developed an analytical solution for calculating drawdown during groundwater pumping next to a river assuming that regions beneath the riverbed are always fully saturated. Fox and Durnford (2003) studied the unsaturated zone using an analytical method for a RBF system with a single vertical well. Hubbs (2006a) provided a few general methods to predict riverbed shear stresses as an indicator of riverbed scour. Brunner et al. (2009) used 1D and 2D models of natural systems (i.e., without accounting for the impact of time-varying near-river pumping) to determine the critical factors that affect the distance between the surface water and disconnected water table. These studies describe a specific mechanism or component, and the analytical solutions are limited to specific geometries and boundary conditions.

In addition, numerical methods have been applied in previous research for assessing particular aspects of RBF systems. For example, 1D (Constantz et al., 2003) and 2D (Cox, et al., 
2007; Su, et al., 2004) numerical models have been used to investigate the use of heat as a suitable tracer to study the river-groundwater interaction. Schubert (2002) used a 3D groundwater flow and transport model to study the impact of the river flow dynamics on riverbank filtration processes. Although a constant riverbed permeability was used in their models, they concluded that the permeability of clogged areas varies with the dynamic hydrology and cannot be regarded as constant. Wett (2006) built a 3D model to study the interplay between riverbed clogging and infiltration. He concluded that feedbacks between clogging and infiltration exist along the bank stretch (i.e., higher infiltration promotes riverbed clogging and riverbed clogging reduces infiltration) although the feedback was not included in his model. Chen and Chen (2004a) applied a numerical model and concluded that a lower riverbed or aquifer permeability restricts the extension of the storage zone in the area below the channel and in the river banks. Using a sensitivity analysis of a pumping test, Chen and Chen (2004b) investigated the data requirements that may reduce the statistical correlations among hydraulic parameters inferred by inverse modeling. Su et al. (2007) built a 3D model to study the unsaturated zone developing beneath a riverbed, whose results show that a higher ratio of aquifer permeability to riverbed permeability results in a larger unsaturated region. The analytic element method has been applied to model flow to radial collector wells (Bakker, et al., 2005). However, the solutions are limited to steady-state flow and situations where the drawdown of the uppermost layer is relatively small so the conductance of that layer can be approximated by an average conductance.

The objective of this study is to identify the controlling factors and their couplings that impact sustainability of an RBF system and to gain insights into related processes through a numerical framework that permits simultaneous consideration of several hydrological (e.g., 
aquifer and streambed properties) and operational factors (e.g., pumping rate, dam operation) that affect infiltration processes. Our study is performed at the Wohler Site, located in Sonoma County, California, where RBF methods are used for drinking water supply, and where an inflatable dam is used to manage river stage. Our numerical models simulate regional, 3D unsaturated flow in the vadose zone and saturated groundwater flow in the deeper aquifer in response to seasonal dynamics, dam function, and pumping operations. Interaction between the river and aquifer is simulated through a boundary condition that depends on river stage; we refer to our models as the river-aquifer models. These models serve as a framework for integrating the disparate datasets at the site and for evaluating the impact of various factors on the development of unsaturated zones, riverbed clogging, and ultimately water production. We quantify riverbed clogging by calibrating a time-dependent permeability function based on water level data. The function is evaluated at times when pumping rate, river stage, and temperature reversals occur. This new approach captures the hydrodynamic effects of all potential clogging mechanisms as is needed to optimize RBF operations. Our study advances and refines the existing conceptual model of the Wohler Site by evaluating the factors that most significantly control water production. Furthermore, we gain understanding of how and when riverbed clogging occurs as a result of hydrological processes and dam operation by means of a dynamic streambed permeability function. This information will serve as the basis for developing guidelines for sustainable river-aquifer system management near a river.

We provide a description of the study site, followed by a discussion of the development and calibration of a regional model along a stretch of the Russian River, which is used to simulate the regional effects of river-aquifer interaction and collector well interference. In addition, a refined, more local-scale model near two collector wells was developed and used to 
explore factors influencing clogging and the development of an unsaturated zone. The simulation and sensitivity studies show the relevance of the river-aquifer interaction for a sustainable management of an RBF system is discussed.

\section{Wohler Study Site}

The Russian River emanates from Mendocino County and flows south into Sonoma County along the western edge of the Santa Rosa Plain, and then flows westwards into the Pacific Ocean. Our study area includes a stretch of the Russian River near Wohler, Sonoma County, Northern California (Figure 1). The Sonoma County Water Agency (SCWA) operates a RBF system that includes six horizontal collector wells and seven vertical wells with a maximum total capacity of over 92 million gallons per day (mgd; $4030 \mathrm{~kg} / \mathrm{s}$ ), in addition to about $20 \mathrm{mgd}$ $(880 \mathrm{~kg} / \mathrm{s})$ standby capacity. The system provides drinking water to 600,000 people in Sonoma and Marin Counties. Three of these collector wells and 13 surrounding monitoring wells located at the Wohler site are included in our study. Collectors 1 and 2 (marked as C1 and C2 in Figure 1) are about $75 \mathrm{~m}$ apart. Collector 6 (C6) is about $700 \mathrm{~m}$ upstream from C1 and C2. Figure 2 shows a schematic of a typical collector well, which consists of nine to twelve horizontal laterals extending in a radial direction from a large-diameter caisson to near or beneath the river. An inflatable dam is located downstream of these three collector wells. This dam is used to locally raise the upstream river water level during the dry season with the goal to enhance river infiltration and thus drinking water production. The dam is typically lowered in the fall as water demands decrease and river flows increase.

Aquifer tests have been conducted to evaluate surface-groundwater interaction, and several studies have been performed at the Wohler site to explore the hydrodynamics associated 
with the RBF pumping. Constantz et al. (2003) used heat as a tracer to quantify streamgroundwater exchange. Su et al. (2004) used temperature measurements to characterize the hydraulic conductivity field in a 2D numerical model. In addition to heat, Cox et al. (2007) used chloride concentration and specific conductance to estimate flow travel times from the river to nearby wells. A 3D numerical model (Trotta, 2004) was used to investigate if the proposed siting of Collector 6 will reduce capacity of Collectors 1 and 2. Su et al. (2007) developed a 3D numerical model with simplified river geometry and constant river stage (i.e., dam operation was not considered) for a region near Collectors 1 and 2 to study the development of an unsaturated zone beneath the riverbed. Although the model was not calibrated, simulation results from a number of scenarios with different riverbed and aquifer permeabilities show that a higher ratio of aquifer permeability to riverbed permeability results in a larger unsaturated region (Su et al., 2007). Constantz et al. (2006) calibrated riverbed conductivity against temperature data and, Cox et al. (2007) analyzed both temperature data and specific conductance at different locations, both using a 2D model. These calibration results indicated that riverbed clogging occurs in the area near Collectors 1 and 2.

We build on these previous studies by developing and calibrating 3D river-aquifer models that include all key components that have been identified as potentially important for RBF systems. We use the developed model to explore (1) hydrological communications among wells and between the river and groundwater, (2) inflatable dam operation and seasonal effects on pumping capacity, and (3) potential riverbed desaturation and clogging mechanisms at the Wohler site. The developed models include Collectors 1, 2, and 6 and incorporate the irregular shape of the river and model boundaries. 
The locations of the thirteen monitoring wells are shown in Figure 3a. Water table data are available at different times for different wells between 2005 and January 2008. These data are used for model calibration. A formal sensitivity analysis is performed to examine hydrologic interference and inflatable dam operation effects.

The alluvial aquifer in the studied area is bounded laterally and at the bottom by bedrock of the Franciscan Complex, which is considered to be relatively impermeable compared to the alluvial aquifer. This impermeable bedrock morphology is used as the model boundaries, shown as the blue lines in Figure 3a. The aquifer is mainly composed of sands and gravels, interbedded with thin layers of silt and clay; such layering is likely to lead to anisotropy. Aquifer permeabilities measured from pumping tests range from $2.4 \times 10^{-10}$ to $6.5 \times 10^{-10} \mathrm{~m}^{2}\left(2.4 \times 10^{-3}\right.$ to $\left.6.5 \times 10^{-3} \mathrm{~m} / \mathrm{s}\right)(\mathrm{Su}$, et al., 2007). The collector well laterals are located at elevations ranging from 4.5 to $7.2 \mathrm{~m}$ below sea level, approximately $16 \mathrm{~m}$ below the riverbed. Under typical conditions (without excessive pumping), the water table is connected to the riverbed.

\section{Regional River-Aquifer Model: Development, Calibration, and Simulation}

We first develop a regional scale model to study the key factors affecting sustainable aquifer recharge, maximum pumping capacity, and development of an unsaturated zone beneath the riverbed. The forward model simulations were conducted using TOUGH2-EOS9 (Pruess, 1999; Finsterle, 2007), a module that solves the Richards equation for saturated and unsaturated flow. In this module, gas is considered as a passive bystander and temperature effects are ignored. The inverse modeling tool, iTOUGH2 (Finsterle, 2004), was used for automatic model calibration and systematic sensitivity analyses. 


\section{Forward Model Setup}

The areal extent covered by the regional river-aquifer model is about $1 \mathrm{~km}^{2}$. The model is $36 \mathrm{~m}$ in depth, containing 19 layers with non-uniform layer thicknesses. The riverbed is modeled as a $1 \mathrm{~m}$-thick layer; the collector laterals are contained in a $0.2 \mathrm{~m}$-thick layer (the laterals have a diameter of $0.2 \mathrm{~m}$ ). The remaining layers have a thickness of $1 \mathrm{~m}$, except the layers above the riverbed and below the laterals, which are slightly thicker. The mesh (Figure 3b) was generated using WinGridder (Pan et al., 2001). It consists of about 25,000 grid blocks, with higher resolution around the collectors and in the riverbed area. The relatively impermeable boundaries corresponding to the bedrock were obtained from Trotta (2004) where no-flow boundary conditions were applied. The bottom and top of the model are at elevations of $-16 \mathrm{~m}$ and $20 \mathrm{~m}$ (relative to sea level), respectively. The shape and width of the river were obtained from a Google map. We assumed that river morphology does not significantly change as a function of river stage and time. The upstream and downstream boundaries are hydraulically connected to the regional aquifer. Therefore, prescribed head boundary conditions with time-dependent values obtained from two nearby monitoring wells were specified. The top of the model was given an atmospheric boundary condition, except for the elements representing the river, where a timedependent prescribed pressure was specified according to the river stage. The impact of precipitation and evapotranspiration on the regional groundwater level is approximately accounted for through the time-varying upstream and downstream boundaries. Fox and Durnford (2003) have shown that the transition from the saturated flow regime to a gravity-driven unsaturated flow regime is rapid. In a standard groundwater flow model, this transition results in a change of the boundary condition from constant head to constant flux, where the flux is related to the conductance of the least permeable layer between the river and the water table (usually 
that of the riverbed). In our simulation, however, unsaturated flow in the vadose zone is explicitly simulated, the river boundary remains being represented by a (potentially timedependent) Dirichlet boundary condition, and the recharge rate is calculated as part of the solution for the given unsaturated hydraulic properties of the subsurface.

Water intake through the fan of collector laterals of variable lengths is approximated in the model by a rectangular domain of increased permeability. The aspect ratio and area of this domain is consistent with the footprint covered by the laterals. A time-varying Neumann boundary condition with the recorded pumping rate is applied at the element where the caisson is located.

Initial conditions were obtained by running the model for half a year with average stresses (river stage, boundary conditions and pumping rates), followed by one-month model spin-up period using actual stresses as they prevailed before and right up to the beginning of the calibration period.

\section{Model Calibration}

Water table measurements at all thirteen monitoring wells were available during the period from June 1, 2006 to July 10, 2006, and thus this 40-day period was selected for model calibration. Water table elevations were measured hourly, although we used an increment of 5 hours for model calibration. At each calibration time, drawdown at each monitoring well was calculated as the water table elevation at that time minus the initial water table at that well. Simulations were performed under isothermal conditions, using a constant temperature of $20^{\circ} \mathrm{C}$ (the air temperature during that period ranges from $6^{\circ} \mathrm{C}$ to $39^{\circ} \mathrm{C}$, with an average of $19^{\circ} \mathrm{C}$; soil temperature ranges from $16^{\circ} \mathrm{C}$ to $22^{\circ} \mathrm{C}$, with an average of $19^{\circ} \mathrm{C}$ ). In the first inversion, only three 
uncertain parameters were subject to estimation: vertical and horizontal aquifer permeabilities, and riverbed permeability.

The initial calibrated horizontal and vertical aquifer permeabilities were $3.45 \times 10^{-10} \mathrm{~m}^{2}$, and $1.10 \times 10^{-11} \mathrm{~m}^{2}$, respectively. The riverbed permeability was $1.00 \times 10^{-12} \mathrm{~m}^{2}$. These serve as the base values for the subsequent sensitivity analyses as will be described below. Figures 4a and 4b show the pumping rates for C1 and C6 during the calibration period. C1 was mostly pumped with a rate of 10 or $20 \mathrm{mgd}$, interspersed with periods of inactivity. C6 was pumped at 10 or 30 mgd (not shown is C2, which was included in the model but was rarely turned on). Figures 4c and 4d show the measured and calculated drawdowns at the adjacent monitoring wells TW17 and TW03 (the pilot-point results will be discussed below). The pumping schedules exhibit a complicated pattern. Even during the periods with almost constant pumping rates, the corresponding drawdown shows fluctuations that can not be explained using standard wellbore analysis methods. By using numerical modeling, we were able to capture some of the fluctuations that are caused by changes in river stage, upstream boundary conditions, and pumping rate.

While the overall behavior is captured, there are some remaining discrepancies. Part of the fitting discrepancy is likely the result of aquifer heterogeneity. To include heterogeneity and to adjust its pattern during data inversion, we used geostatistical simulations in combination with the pilot point method (Gomez-Hernandez, et al., 1997; RamaRao, et al., 1995). In this method, permeability values at select pilot points are estimated. The pilot points are then used as conditioning points during the geostatistical simulation of a random, spatially correlated permeability field. By changing pilot point values, the specific pattern of heterogeneity was adjusted over the entire model domain, while maintaining its overall geostatistical properties. We 
used ten pilot points, which were distributed horizontally (in the X-Y plane) and also located at different elevations. The horizontal locations of these points are shown in Figure 3b. In this case, the calibrated properties are riverbed permeability, average aquifer horizontal permeability, aquifer anisotropy ratio, and permeability modifiers at the ten pilot points. Figure 3b shows the contours of the logarithm of the estimated horizontal permeability field at the elevation of the riverbed. The corresponding simulated drawdowns (blue curve) are plotted in Figures 4c and 4d. Although using pilot points only slightly improved the model fit to water table measurements at these two wells, the reduction in the total objective function (from the calibrated homogeneous model to the calibrated heterogeneous model) is reduced by $40 \%$, indicating an overall better agreement between the model and the data. However, discrepancies cannot be entirely resolved due to the impossibility of capturing the random component of the spatial variability and other model simplifications, including assumptions about boundary conditions, model geometries, conceptual model, and errors due to numerical discretization.

Figure 5 shows a saturation profile at C1 (X-Z profile) and C6 (Y-Z profile) at the end of the calibration period. At both locations, the simulations predict the development of an unsaturated zone directly beneath the riverbed. The key factors that affect the development of this unsaturated zone will be investigated in the next section. Figure 6 shows contour maps of water saturation and drawdown at the end of the calibration period at a few elevations. Notice that the drawdown near Collector 6 at the elevation of the laterals exceeds 10 meters, a value higher than the drawdown in the layers above. This head gradient is the driving force supplying water to the laterals. However, this does not imply that a significant depression of the water table occurs. The pressure head in the laterals is imposed by the water level in the central caisson. Once the water level in the caisson reaches the elevation of the laterals, the head cannot be 
further reduced despite the fact that the water table in the aquifer has not yet reached the laterals. This behavior is specific to the hydraulics of a well configuration with a caisson and laterals. Extraction rates that lead to atmospheric pressures in the laterals thus indicate that the well pumping capacity is reached.

\section{Model Refinement to Study Riverbed Clogging}

To understand which processes are affecting riverbed clogging at the Wohler site, and what operational measures can be taken to prevent riverbed clogging as part of optimal surface water and groundwater management, in this Section we focus our modeling effort on the region near C1 and C2, where clogging has been observed (Constantz, et al., 2006). We refine the previous mesh in the region near Collectors 1 and 2 (each element is $5 \mathrm{~m}$ along $\mathrm{X}$ and $\mathrm{Y}$ directions). To reduce the computational cost, we coarsen the mesh near Collector 6.

We develop and use the refined model to explore the impact that river stage, season, dam operation, and pumping have on clogging near Collectors 1 and 2. We postulate that riverbed clogging is gradual, occurs during summer, and can be reversed by flushing, which is associated with storms and dam lowering during winter. We further suggest that increased deposition of fine particles occurs due to pumping-induced infiltration, and that the presence of an unsaturated zone below the river may promote clogging. To test these concepts, we permit the riverbed permeability to change as a function of time. We calibrate the riverbed permeabilities at different times against the water table data over a sufficiently long period, given that different clogging mechanisms may be manifest at different times. The focus of the study is on the local areas of Collectors 1 and 2. Aquifer permeability are assumed to be relatively homogeneous, but is 
considered uncertain and is thus determined by calibration using the data from monitoring well TW17, which is located near Collectors 1 and 2.

The calibration period is from January 24 to November 20, 2007. A major storm occurred during this period - on February 22-and the dam was lowered between February 6 and 8 to prepare for the expected increase in river flow, and raised again on March 27-30. In addition to this major event, the dam has been raised and lowered one more time during the calibration period. The pumping rate of Collector 1 , the elevation of the river stage at the dam during this period, and temperature are shown in Figure 7. Seven temporal permeability calibration points were selected based on the time of major stress changes, including the change in river stage or pumping rate and temperature reversals. Riverbed permeability is estimated at these points in time, and assumed to change linearly between them. The effects of river infiltration rate and river velocity are not explicitly considered in the selection of these temporal points, because no direct measurements of these quantities are available. However, their effects are partially considered as they tend to change with pumping rate, dam operation, and storm events.

The calibrated permeability values are listed in Figure 7. In addition, the calibrated local horizontal aquifer permeability is $2.1 \times 10^{-10} \mathrm{~m}^{2}$, and vertical permeability is $1.2 \times 10^{-10} \mathrm{~m}^{2}$. Gas saturation at $1 \mathrm{~m}$ beneath the riverbed and river infiltration calculated from the calibrated model are shown in Figure 8.

\section{Analysis and Discussion}

In this section, we use the developed models to explore the impact of: 
- Hydrogeological characteristics (aquifer permeability and riverbed permeability) and operational characteristics (river stage associated with inflatable dam operation, pumping rate) on river infiltration and thus on water production;

- Aquifer anisotropy, contrast between riverbed and aquifer permeability, and daminfluenced river stage and pumping rates on the development of an unsaturated zone;

- Collector wells interference, riverbed permeability, and river stage on maximum pumping capacity;

- Season, temperature, and dam operation on riverbed clogging.

Analyses addressing the first three topics are conducted using the calibrated regional model described previously, while analysis of the final topic is conducted using the refined localscale model with riverbed permeability represented as a function of time.

\section{River infiltration}

Sensitivity analyses were conducted using the calibrated regional model to study various factors that can potentially impact infiltration and thus water production associated with RBF. Specifically, the sensitivities of the following six uncertain parameters to river infiltration were obtained: aquifer horizontal permeability, aquifer vertical permeability, riverbed permeability, river stage, Collector 1 pumping rate, and Collector 6 pumping rate. The scaled sensitivity coefficient is calculated as the ratio of the change of system response (the amount of river) to the change of the uncertain parameter, scaled by their respective variabilities. The calculated sensitivity coefficients with time are plotted in Figure 9. 
These sensitivity results show that (1) the riverbed permeability is the dominant factor impacting river infiltration, as expected; (2) for a given riverbed permeability (provided riverbed permeability is sufficiently large), the pumping rate and river stage also affect river infiltration.

While the key factors affecting river water infiltration are potentially controllable, the extent of this control is limited. The amount by which the river stage can be increased by raising the inflatable dam is relatively small and depends on the hydrological conditions in the watershed, which change with season. While it may be desirable to maximize the pumping rate, adverse effects (specifically the development of an unsaturated zone beneath the riverbed, and well interference) need to be considered during the RBF management. Induced scouring to increase riverbed permeability is a technical challenge. Finally, correlations among these key factors must be accounted for during control. For example, the riverbed clogging may be partly ameliorated by lowering the inflatable dam, thus increasing flow velocity in the river. However, this will lower the river stage. As a result, the wetted surface area of the riverbank is reduced, leading to a smaller recharge surface area relative to high river stage conditions. Moreover, the hydraulic head gradient driving infiltration is reduced. All these factors potentially promote a hydraulic disconnection between the river and groundwater.

\section{Development of an unsaturated zone}

The saturation at a point beneath the riverbed is selected near Collectors 1 and 2 to numerically examine the development of an unsaturated zone as a function of riverbed permeability, horizontal aquifer permeability, horizontal to vertical permeability anisotropy, and river stage. Anisotropy in aquifer permeability of sedimentary systems can vary from 2 to 500 (Chen and Chen, 2003) due to the layered structure of alluvial deposits. Figure 10a shows the saturation at this point as a function of riverbed permeability and horizontal aquifer permeability 
when the anisotropy ratio is 30 , which is consistent with our homogeneous model calibration. This figure suggests that when the riverbed permeability is high, the zone below the river is always fully saturated. With decreased riverbed permeability, an unsaturated zone develops, unless aquifer permeability is also low. This suggests that the development of an unsaturated zone depends on the contrast between riverbed and aquifer permeability. Figure 10b is a similar diagram but with an anisotropy ratio of 2, representing an increased vertical aquifer permeability and a value that is in line with that used by Su et al (2004) (Among the three anisotropy values: 1, 2 and 5, they concluded that anisotropy ratio of 5 gives the best fit). The saturation is lower in this case relative to the one shown in Figure 10a. This is due to the overall increase of effective aquifer permeability, which leads to a higher contrast between aquifer permeability and riverbed permeability. In general, alluvial aquifers exhibit relatively strong anisotropy due to the layered structure of the fluvial deposits.

Figure 10c shows the saturation as a function of river stage and riverbed permeability given an anisotropy ratio of 30. This figure suggests that if the riverbed permeability is low (e.g.,

lower than $10^{-12} \mathrm{~m}^{2}$ ), increasing the river stage does not prevent the development of the unsaturated zone beneath the riverbed, which confirms that riverbed permeability is the limiting factor for river infiltration. Only when the riverbed permeability is sufficiently large can the unsaturated zone be reduced by raising river stage.

\section{Pumping capacity}

In this paper, pumping capacity is defined as the maximum pumping rate that can be sustained (e.g., the rate that will not cause aquifer desaturation and air intake in the laterals of the collector wells). Figure 11 shows pumping capacity as a function of river stage and riverbed 
permeability for the following cases: (a) only Collector 1 is pumping; (b) only Collector 6 is pumping; and (c) both collectors are pumping.

These figures show the significant impact riverbed permeability has on pumping capacity, outweighing the effects of a variable river stage, which can affect pumping capacity only if riverbed permeability is sufficiently large. The maximum amount of infiltration, determined by the pumping capacity, is almost fixed for a given riverbed permeability (with a little variation for different river stages). This implies that increasing river infiltration by increasing the groundwater pumping rate can only be achieved if the riverbed permeability is sufficiently large, which requires periodic scouring of the riverbed. These figures also show that the total pumping capacity of both collectors is almost the same as the sum of the pumping capacities from each individual collector, which means that Collectors 1 and 6 are far enough apart not to significantly interfere with each.

These simulations suggest that (1) the efficiencies of collector wells are primarily controlled by riverbed permeability, as long as it is substantially lower than aquifer permeability, as expected; river stage/dam operation affects pumping capacity but the effect is small even with sufficient riverbed permeability; (2) the efficiency is only affected by river stage (inflatable dam operation) if riverbed permeability is relatively high; (3) pumping in Collectors 1 and 2 does not significantly affect pumping capacity of Collector 6, and vice versa; and (4) the development of an unsaturated zone is mainly affected by the contrast of riverbed permeability and aquifer permeability (only when riverbed permeability is sufficiently large can the development of an unsaturated zone-and thus pumping capacity — be controlled by adjusting the river stage through dam operation. 


\section{Riverbed clogging}

Figure 7 shows that the estimated riverbed permeability varies over time, with particular behavior identified in three different phases as is described below.

- Phase I extends from December 2006 to January 2007, which represents a period directly following a significant storm at the end of November 2006 and smaller subsequent and intermittent rainfalls. The dam was down during this period. The calibration results show an initial riverbed permeability of $6.1 \times 10^{-13} \mathrm{~m}^{2}$ in January 2007. This phase serves as the spin-up period and marks the beginning of the calibration period.

- Phase II extends through the rainy season (January-March), when the dam was down and thus river flows at a low stage. During this phase, Figure 7 shows the calibrated riverbed permeabilities increase, confirming our assumption that clogging can be partly reversed during periods of high river velocity. A relatively high jump of the calibrated riverbed permeability at the end of February is likely due to the storm in February. It appears that the occasional desaturation under the riverbed and intensive infiltration, observed during this time period on Figure 8, did not last long enough to induce significant clogging. Our findings for this period are in agreement with the experimental findings of Gorman (2004), whose point estimate of hydraulic conductivity near TW01 increased between September 2003 and March 2004 by slightly more than one order of magnitude

- Phase III extends from March through November and represents a relatively dry period. The dam was slightly lowered once (end of April) and raised immediately 
afterwards; this minor operation is not believed to have impacted riverbed clogging. Based on our assumption that flushing of the riverbed due to high flow velocity in the river caused by the winter storm and/or lowering of the dam is the only mechanism to reverse clogging, we expected a decreasing riverbed permeability during these months caused by gradual clogging due to relatively stagnant river water after the dam was raised in March. Figure 7 shows that permeability is decreased by approximately a factor of three. Again, this result is consistent with the estimation result by Gorman (2004), who observed a decrease in hydraulic conductivity near TW01 between June and September 2003. Figure 7 reveals that the calibration results are in general agreement with the decreasing trend, with the exception of the period between June and August. During that period, the infiltration rate was relatively high (see Figure 8). This is due to the high total pumping rate (Collector 2 was also pumped at about $10 \mathrm{mgd}(440 \mathrm{~kg} / \mathrm{s}))$. The high infiltration rate combined with relatively low permeability (compared to the rate at the beginning of the year) caused the development of the unsaturated zone, as demonstrated by the emerging gas saturation region shown in Figure 8. However, the estimated permeability increased despite the continued pumping and the simulated development of an unsaturated zone beneath the riverbed.

Although the increase in permeability seems to contradict our hypotheses, there are possible explanations for this exception. (1) Our isothermal simulations assume that mechanical clogging is the only process that causes changes in riverbed hydraulic conductivity. However, in reality, hydraulic conductivity is a function of temperature due to viscosity and relative permeability effects. The decrease of water viscosity due 
to temperature increase is mild, i.e., the viscosity is $1.3 \times 10^{-3} \mathrm{~Pa} \cdot \mathrm{s}$ at $10^{\circ} \mathrm{C}$ and $1.0 \times 10^{-}$

${ }^{3} \mathrm{~Pa} \cdot \mathrm{s}$ at $20^{\circ} \mathrm{C}$. However, a much greater temperature dependence of hydraulic conductivity could be caused by the temperature dependence of relative permeability (Constantz, 1982), which is caused by the temperature dependence of the water retention curve (She and Sleep, 1998). No equations have been developed to quantify the temperature dependence of relative permeability. Since this temperature dependence is not included in the model, the effect is reflected in the calibrated riverbed permeability. In other words, this increase in the calibrated riverbed permeability may be caused by the hydraulic conductivity increase with temperature, instead of unclogging of riverbed permeability. (2) The temporal change of riverbed permeability was not properly parameterized, i.e., not enough (or not the right) points in time were selected for permeability calibration. Moreover, permeability may not change linearly with time. (3) The estimated riverbed permeabilities might be biased by other modeling errors, such as boundary conditions and heterogeneity. Figure 12 shows the comparison between measured and calculated drawdown at TW17. A relatively large error is observed around June 8 and August 3 compared to other times. This error could be either caused by modeling errors, or parameterization inaccuracy.

This discussion highlights that riverbed permeability appears to be time-dependent, with a trend of gradual riverbed clogging and riverbed permeability reduction during the summer months when the dam is raised, and a riverbed permeability increase during the winter when higher river flow velocities occur during storms when the dam is lowered. 


\section{Conclusions}

In this study, we developed a numerical modeling approach to jointly consider key properties and processes that impact the hydrodynamics near RBF systems. Unlike most previous studies, which documented such properties and processes separately, we considered their interactions in a coupled modeling and joint analysis framework. We used our regional and local-scale models to integrate disparate datasets collected along a segment of the Russian River at the Wohler site, California, and to perform simulations, sensitivity studies and analyses geared toward (1) understanding the hydrodynamics associated with groundwater pumping near a river, and (2) identifying factors that govern the two common problems that impact the sustainability of RBF operations-unsaturated zone development and riverbed clogging. The regional 3D model was developed to study the effect of river stage, riverbed permeability, aquifer permeability, and pumping rate on the amount of river infiltration. The model includes saturated and unsaturated flow and details of the river morphology as well as time-varying boundary conditions. It uses a simplified representation of the collector well laterals, neglects gas-flow and temperature effects, and does not explicitly simulate the various clogging and scouring mechanisms. The impact of these simplifying assumptions was partly compensated by estimating effective parameters, including a time-dependent riverbed permeability, through calibration of the model against water table data from multiple monitoring wells. This approach of representing riverbed clogging mechanisms and their interactions through estimated effective parameters is a reasonable way to understand the impacts of the clogging on infiltration and to include them in the estimation of water production and the design of RBF systems.

Based on the above analyses, we gained the following insights into RBF processes:

- The efficiencies of collector wells are primarily controlled by riverbed permeability. 
- River stage controlled by dam operation affects pumping capacity only if riverbed permeability is relatively high.

- The development of an unsaturated zone beneath the riverbed is determined by the contrast between the riverbed permeability and aquifer permeability as well as the aquifer anisotropy ratio; only under conditions of sufficiently large riverbed permeability can the development of an unsaturated zone be avoided by raising the dam.

- The riverbed must remain permeable to prevent the hydraulic disconnection between the river and the aquifer.

- The seasonal pattern of riverbed permeability suggests that clogging is caused by sedimentation and deposition of fine-grained material within the riverbed, and cleaning may be achieved by flushing (partly controllable by lowering the dam) and scouring. At the Wohler Site, the model specifically suggests that seasonal effects can be mitigated by a sensible operation of the inflatable dam.

In general, the developed insights should be transferable for guiding the management of the river and pumping systems at other RBF sites. The estimation of effective parameters captures the impact of complex clogging and scouring mechanisms on infiltration dynamics. The calibration step ensures that these clogging effects are included in the model with a sufficient level of accuracy, acceptable for the intended purpose of conducting modeling analysis in support of design, optimization, and other water management tasks. The model presented here fulfills this requirement, even though further refinements (e.g., inclusion of temperature effects and gas phase transport, and explicit simulation of various clogging mechanisms) may further improve the reliability of the predictions. Our study suggests that at locations where experimental quantification of riverbed clogging mechanisms is difficult or expensive, readily 
available measurements (such as water levels in observation wells) can be combined with numerical approaches to develop the correlations between effective riverbed permeability, dam operation, and pumping schedules, which in turn can provide a basis for managing the water resource in a sustainable manner.

\section{Acknowledgments}

The authors wish to thank Jay Jasperse, George Lincoln, Marcus Trotta, and Donald Seymour (Sonoma County Water Agency) for their support, data and insights, and Michael Kowalsky (LBNL) for his help in setting up the forward model geometry. We greatly appreciate the very constructive comments by the three anonymous reviewers and the editor. We acknowledge the

funding support by Sonoma County Water Agency through the U.S. Dept. of Energy under Contract No. DE-AC02-05CH11231. 


\section{References}

Bakker, M., V. A. Kelson, and K. H. Luther. 2005. Multilayer analytic element modeling of radial collector wells, Ground Water, 43 (6), 926-934.

Bouwer, H. 2002. Artificial recharge of groundwater: hydrogeology and engineering, Hydrogeology Journal, 10 (1), doi:10.1007/s10040-001-0182-4

Brunner, P., P. G. Cook, and C. T. Simmons. 2009. Hydrogeologic controls on disconnection between surface water and groundwater, Water Resources Research, 45, W01422, doi:10.1029/2008WR006953.

Caldwell, T. G. 2006. Presentation of data for factors significant to yield from several riverbank filtration systems in the U.S. and Europe. In: Hubbs, S. (ed.). Proceedings of the NATO Advanced Research Workshop on Riverbank Filtration Hydrology, Bratislava, Slovakia, 299-344, Springer, Dordrecht, The Netherlands.

Cardenas, M. B. and V. A. Zlotnik. 2003. Three-dimensional model of modern channel bend deposits, Water Resources Research, 39(6), 1141, doi:10.1029/2002WR001383

Chen, X., and X. Chen. 2003. Effects of aquifer anisotropy on the migration of infiltrated stream water to a pumping well, Journal of Hydrologic Engineering, 8(5), 287-293.

Chen, X., and X. Chen. 2004a. Stream water infiltration, bank storage, and storage zone changes due to stream-stage fluctuations, Journal of Hydrology, 280 (1-4), 246-264. doi:10.1016/S00221694(03)00232-4

Chen, X., and X. Chen. 2004b. Sensitivity analysis and determination of streambed leakance and aquifer hydraulic properties, Journal of Hydrology, 284 (1-4), 270-284. doi:10.1016/j.jhydrol.2003.08.004

Constantz, J. 1982. Temperature Dependence of Unsaturated Hydraulic Conductivity of Two Soils, Soil Sci Soc Am J, 46, 466-470.

Constantz, J., M.H. Cox, and G.W. Su. 2003. Comparison of heat and bromide as ground water tracers near streams, Ground Water, 41 (5), 647-656. 
Constantz, J., G.W. Su, and C. Hatch. 2006. Heat as a ground-water tracer at the Russian River RBF facility, Sonoma County, California. In: Hubbs, S. (ed.). Proceedings of the NATO Advanced Research Workshop on Riverbank Filtration Hydrology, Bratislava, Slovakia, 243-258, Springer, Dordrecht, The Netherlands.

Cox, M. H., G.W. Su, and J. Constantz. 2007. Heat, chloride, and specific conductance as ground water tracers near streams, Ground Water, 45 (2), 187-195. doi: 10.1111/j.1745-6584.2006.00276.x

Finsterle, S. 2004. Multiphase inverse modeling: Review and iTOUGH2 applications, Vadose Zone Journal, 3, 747-762.

Finsterle, S. 2007. iTOUGH2 User's Guide, Report LBNL-40040, Lawrence Berkeley National Laboratory, Berkeley, CA.

Fox, G. A., and D. S. Durnford. 2003. Unsaturated hyporheic zone flow in stream/aquifer conjunctive systems, Advances in Water Resources, 26 (9), 989-1000. doi:10.1016/S0309-1708(03)00087-3

Goldschneider, A. A., K. A. Haralampides and K. T.B. MacQuarrie. 2007. River sediment and flow characteristics near a bank filtration water supply: Implications for riverbed clogging, Journal of Hydrology, 344 (1-2), 55-69. doi:10.1016/j.jhydrol.2007.06.031

Gomez-Hernandez, J. J., A. Sahuquillo, J. E. Capilla. 1997. Stochastic simulation of transmissivity fields conditional to both transmissivity and piezometric data-1, Theory, Journal of Hydrology, 203 (1-4), 162-174.

Gorman, P. D. 2004. Spatial and temporal variability of hydraulic properties in the Russian River streambed, Central Somona County, California. M.S. Thesis, San Francisco State University. San Francisco, California.

Greskowiak, J., G. Massmann, H. Prommer, G. Nützmann and A. Pekdeger. 2005. The impact of variably saturated conditions on hydrogeochemical changes during artificial recharge of groundwater, Applied Geochemistry, 20 (7), 1409-1426. doi:10.1016/j.apgeochem.2005.03.002 
Hubbs, S. 2006a. Evaluating streambed forces impacting the capacity of riverbed filtration systems. In: Hubbs, S. (ed.). Proceedings of the NATO Advanced Research Workshop on Riverbank Filtration Hydrology, Bratislava, Slovakia, 21-42, Springer, Dordrecht, The Netherlands.

Hubbs, S. 2006b. Changes in riverbed hydraulic conductivity and specific capacity at Louisville. In: Hubbs, S. (ed.). Proceedings of the NATO Advanced Research Workshop on Riverbank Filtration Hydrology, Bratislava, Slovakia, 199-220, Springer, Dordrecht, The Netherlands.

Hunt, B. 1999. Unsteady stream depletion from ground water pumping, Ground Water, 37 (1), 98-102.

Pan, L., J. Hinds, C. Haukwa, Y. S. Wu, and G. S. Bodvarsson. 2001. WinGridder-An Interactive Grid Generator for TOUGH, Version 1.0 User's Manual, Report LBNL-42957, Lawrence Berkeley National Laboratory, Berkeley, CA.

Pruess, K., C. Oldenburg, and G. Moridis. 1999. TOUGH2 User's Guide, Version 2.0, Report LBNL43134, Lawrence Berkeley National Laboratory, Berkeley, CA.

RamaRao, B. S., A.M. LaVenue, G. de Marsily, and M.G. Marietta. 1995. Pilot point methodology for automated calibration of an ensemble of conditionally simulated transmissivity fields: 1 . Theory and computational experiments, Water Resources Research, 31 (3), 475-493.

Ray, C., G. Melin, R. B. Linsky. 2002. Riverbank filtration: improving source-water quality, Springer.

Schälchli, U. 1992. The clogging of coarse gravel river beds by fine sediment, Hydrobiologia, 235-236 (1), 189-197. doi: 10.1007/BF00026211

Schubert, J. 2002. Hydraulic aspects of riverbank filtration - field studies, Journal of Hydrology, 266 (34), 145-161. doi:10.1016/S0022-1694(02)00159-2

Schubert, J. 2006a. Experience with riverbed clogging along the Rhine River. In: Hubbs, S. (ed.). Proceedings of the NATO Advanced Research Workshop on Riverbank Filtration Hydrology, Bratislava, Slovakia, 221-242, Springer, Dordrecht, The Netherlands. 
Schubert, J. 2006b. Significance of hydrologic aspects on RBF performance. In: Hubbs, S. (ed.). Proceedings of the NATO Advanced Research Workshop on Riverbank Filtration Hydrology, Bratislava, Slovakia, 1-20, Springer, Dordrecht, The Netherlands.

She, H., and B. Sleep. 1998. The Effect of temperature on capillary pressure-saturation relationships for air water and perchloroethylene water systems, Water Resources Research, 34(10), 2587-2597.

Su, G. W., J. Jasperse, D. Seymour, J. Constantz. 2004. Estimation of hydraulic conductivity in an alluvial system using temperatures, Ground Water, 42 (6), 890-901. doi: 10.1111/j.17456584.2004.t01-7-.x

Su, G., J. Jasperse, D. Seymour, J. Constantz and Q. Zhou. 2007. Analysis of pumping-induced unsaturated regions beneath a perennial river, Water Resources Research, 43, W08421, doi:10.1029/2006WR005389.

Trotta, M. 2004. Technical Memorandum - Results of MODFLOW Simulations Proposed Wohler Collector Well No. 6.

Wett, B. 2006. Monitoring clogging of a RBF-system at the river Enns, Austria. In: Hubbs, S. (ed.). Proceedings of the NATO Advanced Research Workshop on Riverbank Filtration Hydrology, Bratislava, Slovakia, 259-280, Springer, Dordrecht, The Netherlands. 


\section{List of Figures}

Figure 1. Map view of Wohler study site in Northern California, showing of collector wells, and photograph of the inflatable dam downstream locations (provided by SCWA).

Figure 2. Schematic of a collector well. At the Wohler Site, the laterals are located approximately $16 \mathrm{~m}$ below the riverbed and extend from 14 to $55 \mathrm{~m}$ from the central caisson.

Figure 3. (a) Map view of study site, showing model boundary and locations of monitoring and collector wells; (b) regional numerical model, showing surface discretization, well locations, pilot points, and contours of estimated permeability field at the riverbed elevation.

Figure 4. Pumping rate of (a) Collector 1 (C1), (b) Collector 6 (C6); and model fits (red symbols: data; green line: calibration using a homogeneous model; blue line: calibration using the pilot point method) at (c) TW17 near C1 and (d) TW03 near C6 during calibration period.

Figure 5. Vertical saturation profiles near (a) Collector C1 and (b) Collector C6 showing the development of an unsaturated zone beneath the river.

Figure 6. Contour maps of saturation (top) and pressure drawdown (bottom) at different elevations, showing the development of an unsaturated zone (at elevation $8.7 \mathrm{~m}$ ), and lack of significant pressure interference between collector wells.

Figure 7. Timeline of events used for calibration point selection (top); Collector 1 pumping rate and river stage at the dam in 2007 (middle); riverbed permeability calibration results (bottom) 
showing seasonal hydrological and operational activity-related trends that are consistent with expected clogging and scouring mechanisms.

Figure 8. Gas saturation under the riverbed (top) and the amount of infiltration (bottom) in 2007, calculated by the calibrated model.

Figure 9. River infiltration sensitivity to six uncertain parameters, showing the dominant impact of riverbed permeability, pumping rate, and river stage on infiltration rate; aquifer properties are of less significance.

Figure 10. Saturation at $1 \mathrm{~m}$ below riverbed at nearby Collector 1 as a function of (a) riverbed permeability and aquifer permeability with an anisotropy ratio of 30; (b) riverbed permeability and aquifer permeability with an anisotropy ratio of 2; and (c) riverbed permeability and river stage.

Figure 11. Pumping capacity as a function of river stage of riverbed permeability for cases (a) only Collector 1 is producing; (b) only Collector 6 is producing; and (c) both collectors are producing drinking water.

Figure 12. Comparison between measured (red) and calculated (green) water table drawdown at observation well TW17 near Collector 1 during the calibration period. 


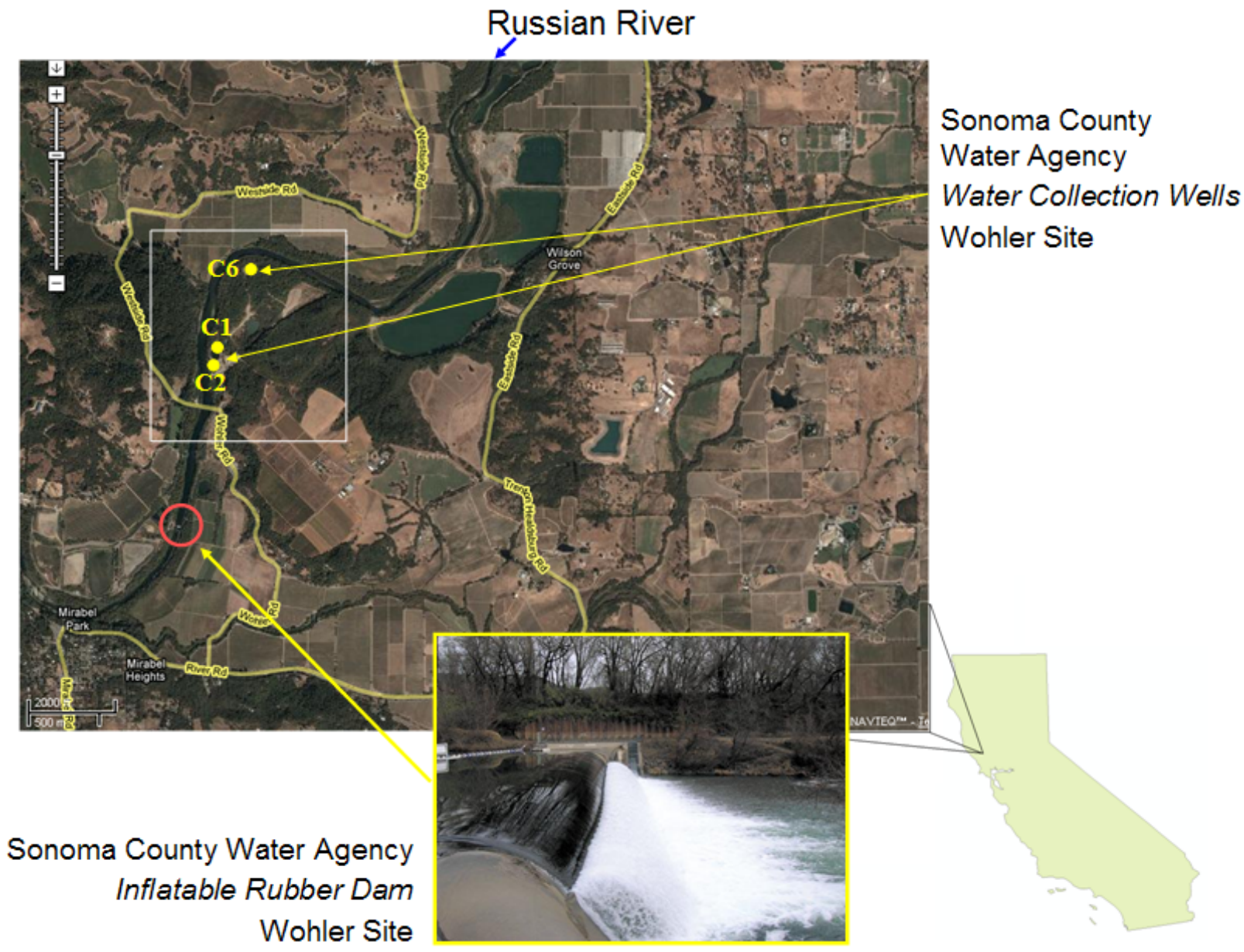

Figure 1 


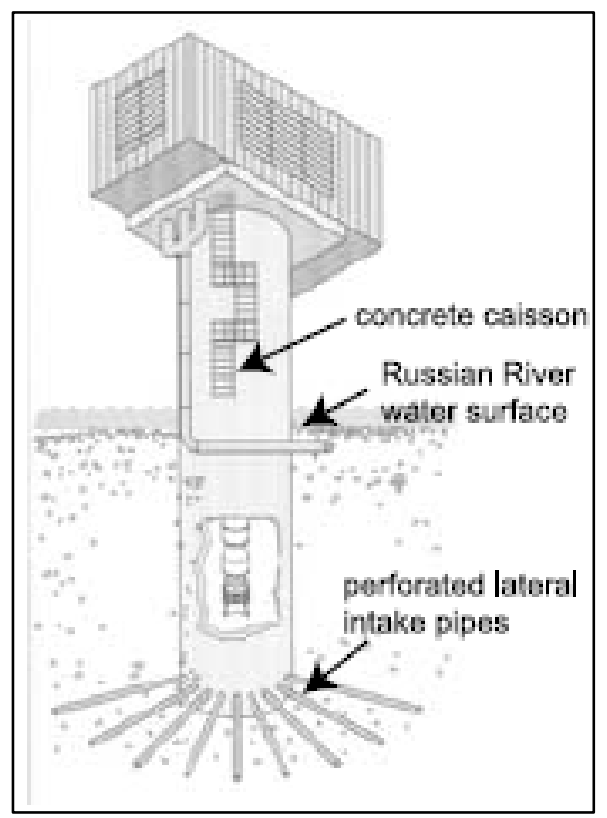

Figure 2 


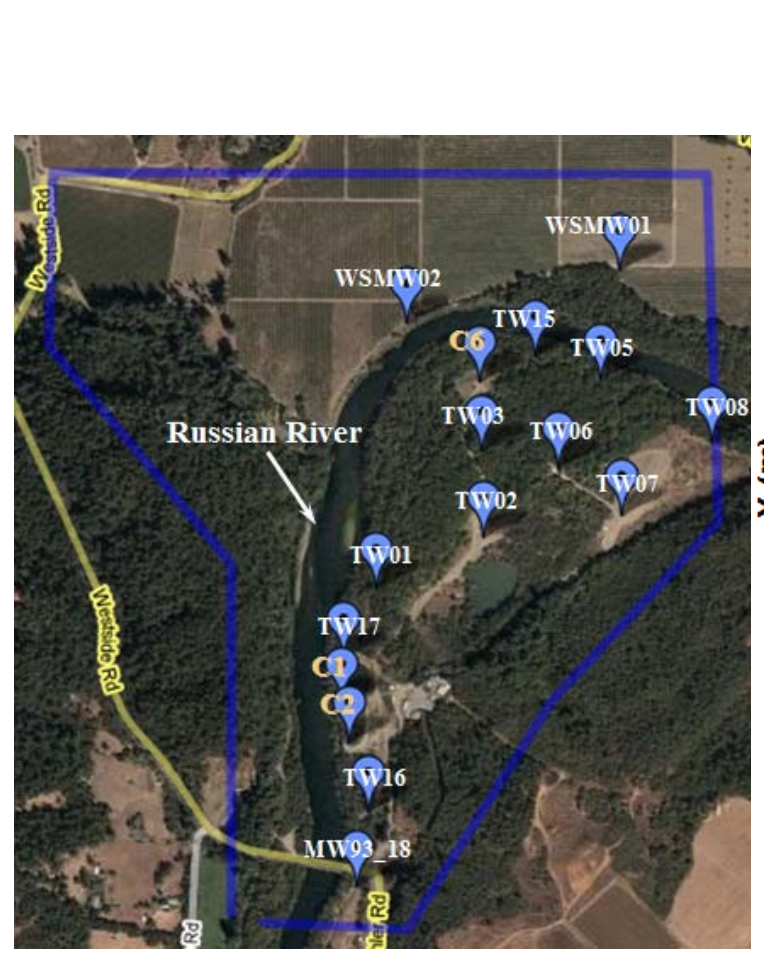

(a)

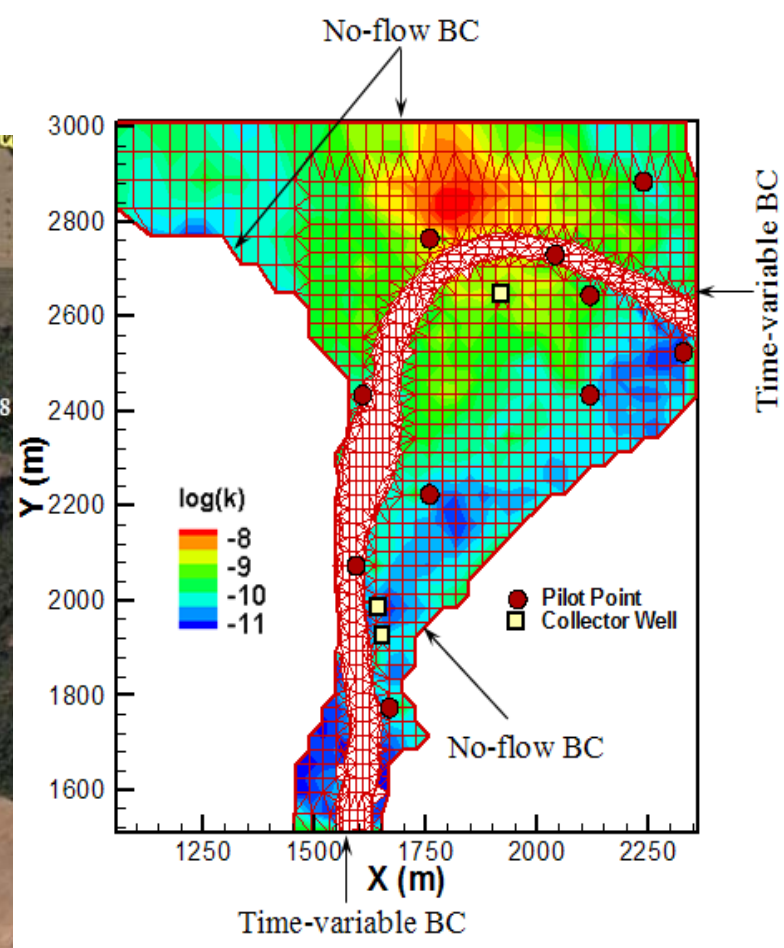

(b)

Figure 3 


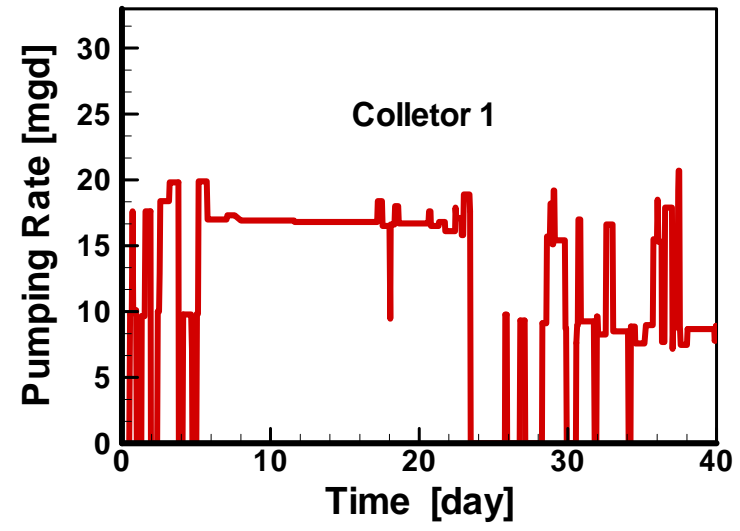

(a)

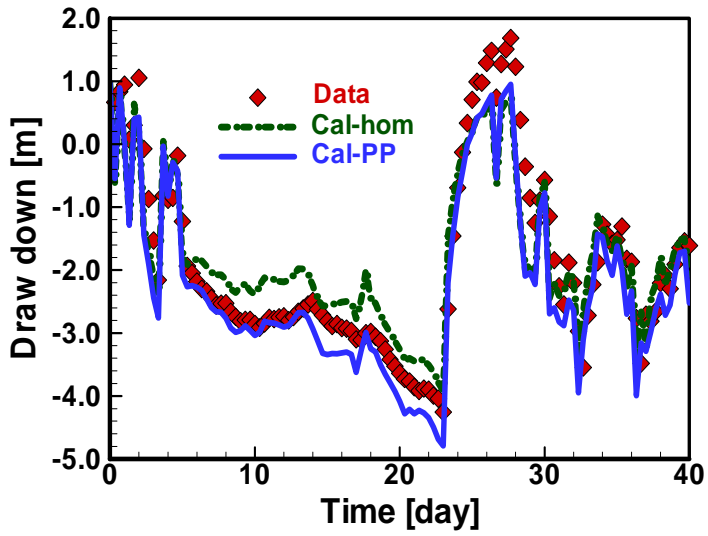

(c)

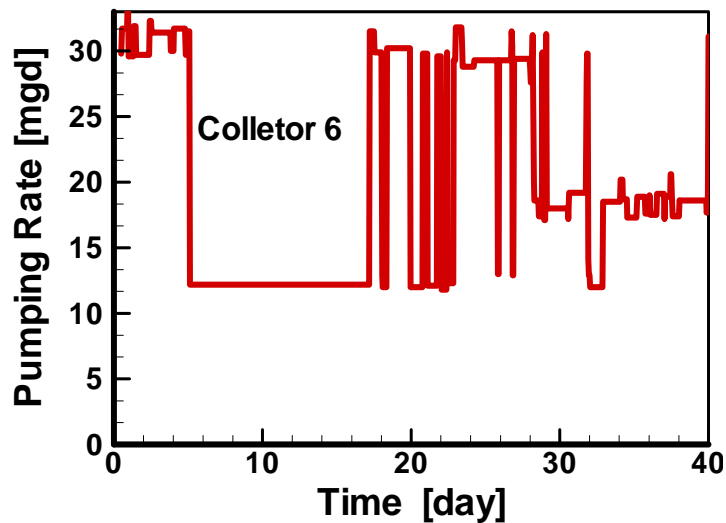

(b)

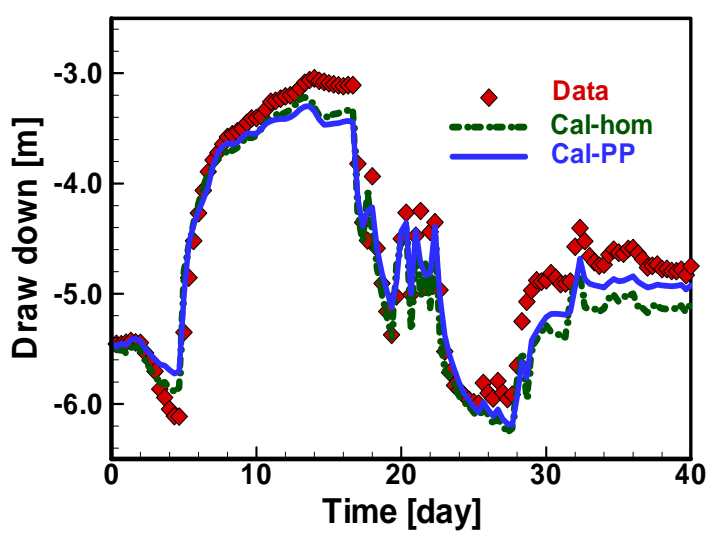

(d) 

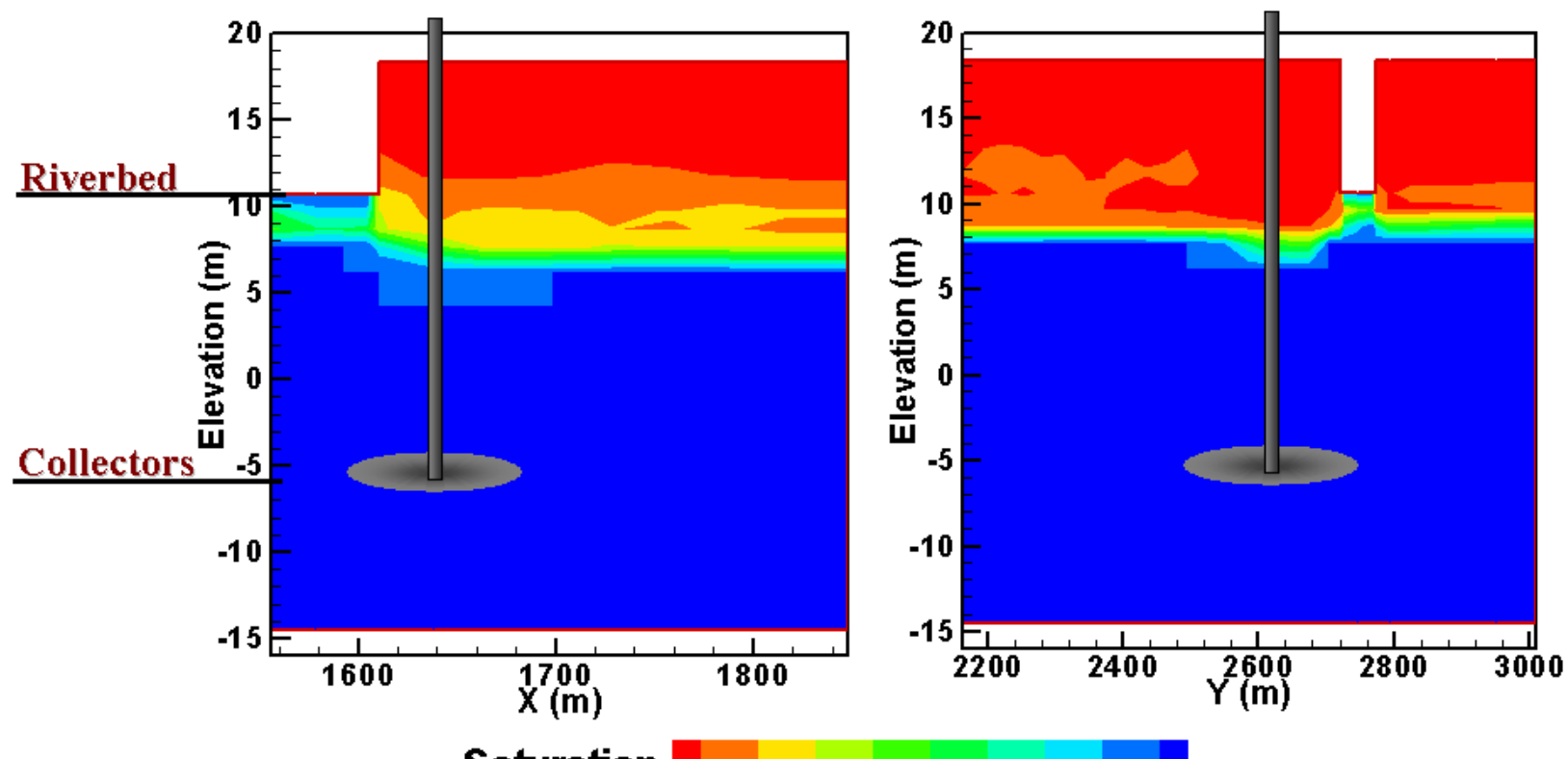

Saturation

0.20 .30 .40 .50 .60 .70 .80 .91

(a)

(b)

Figure 5 

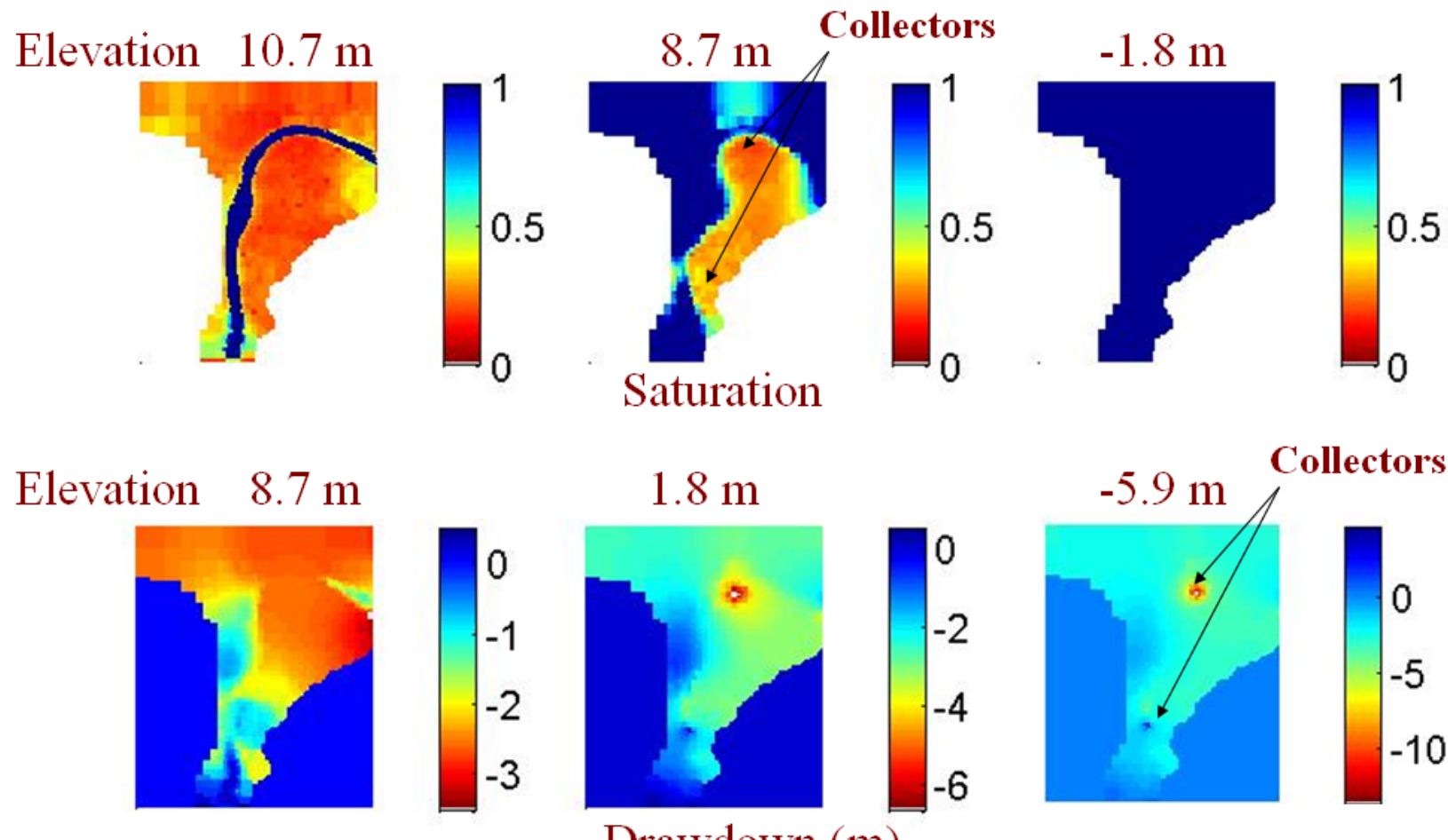

Drawdown (m)

Figure 6 


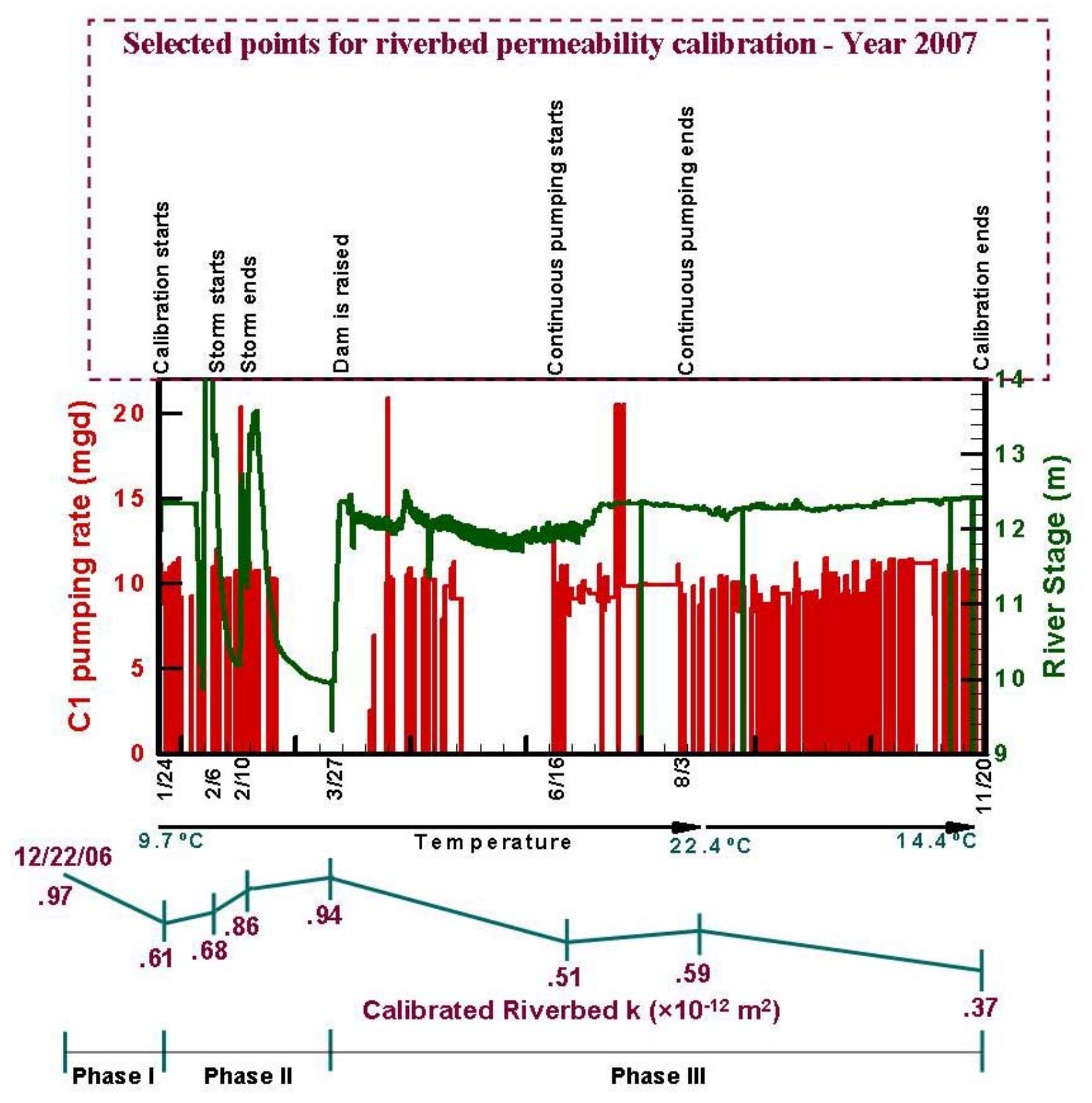

Figure 7 


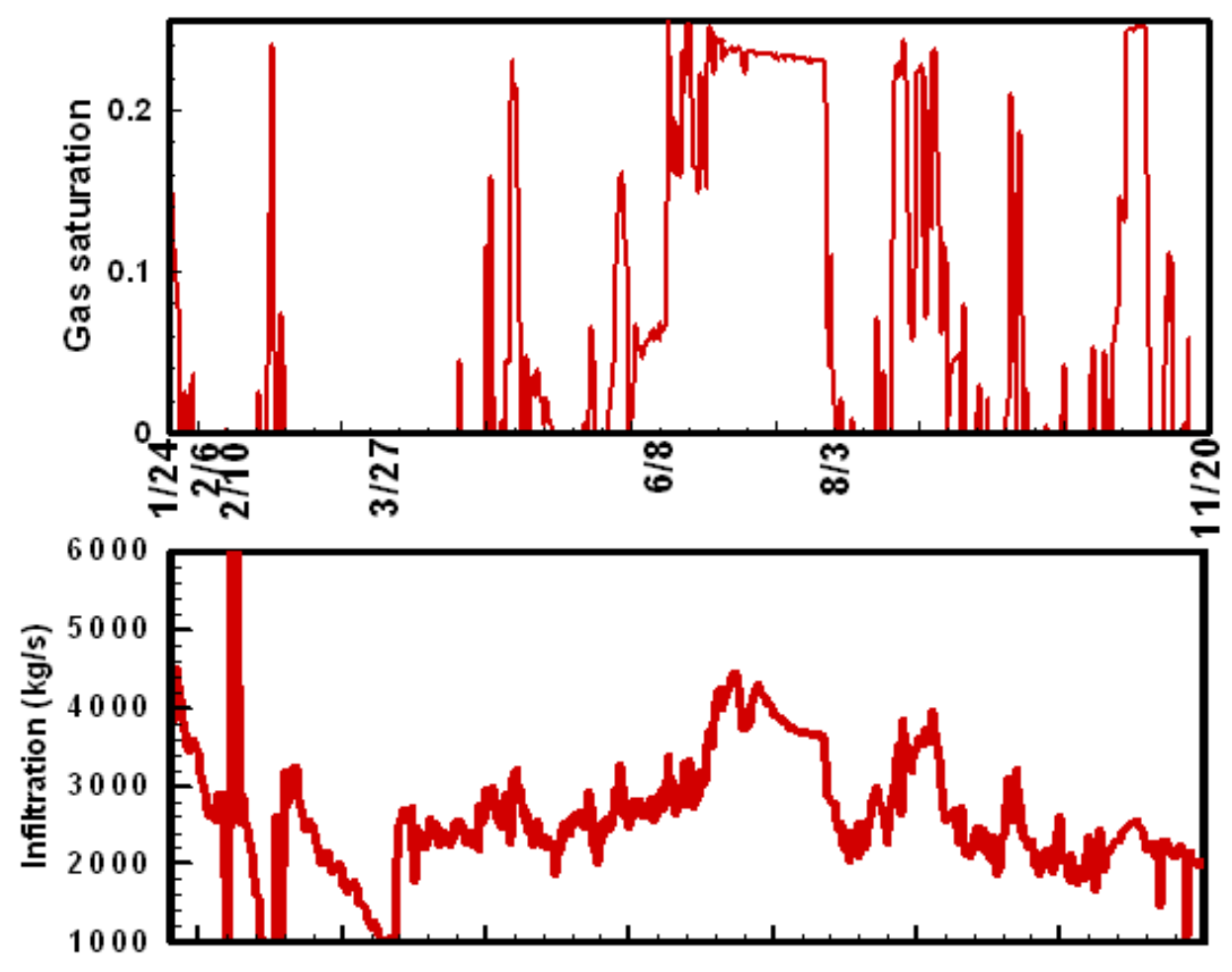

Figure 8 


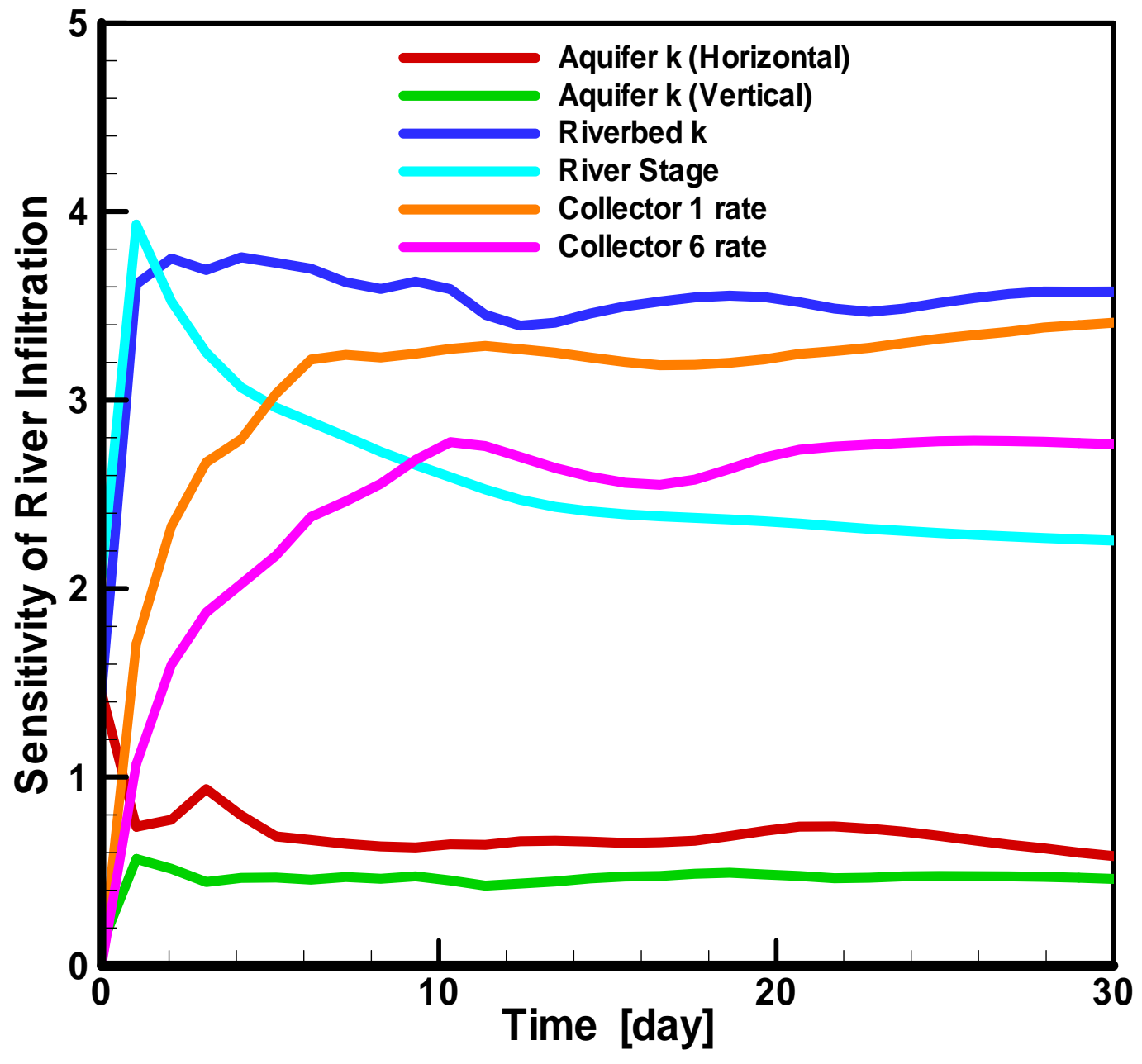

Figure 9 


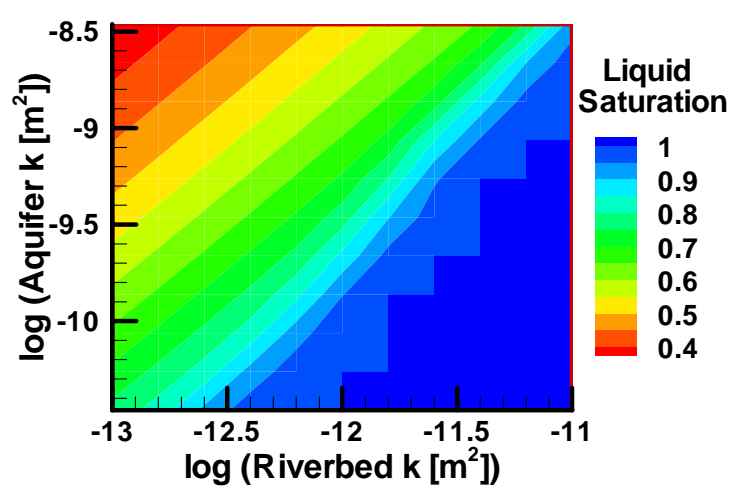

(a)

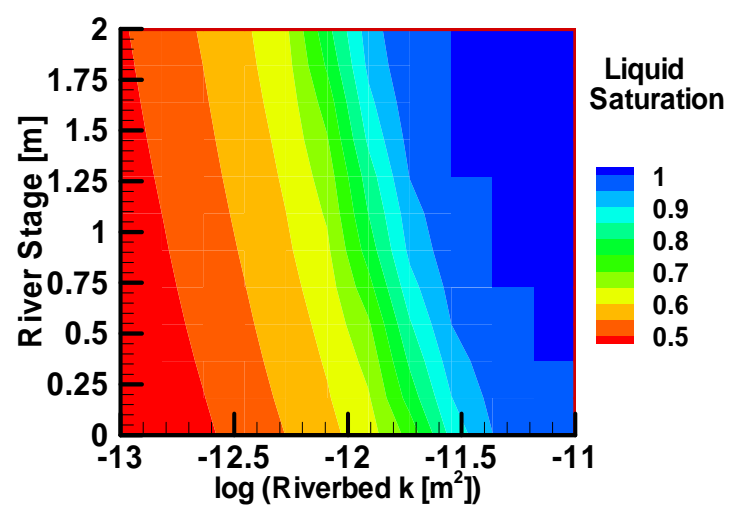

(c)

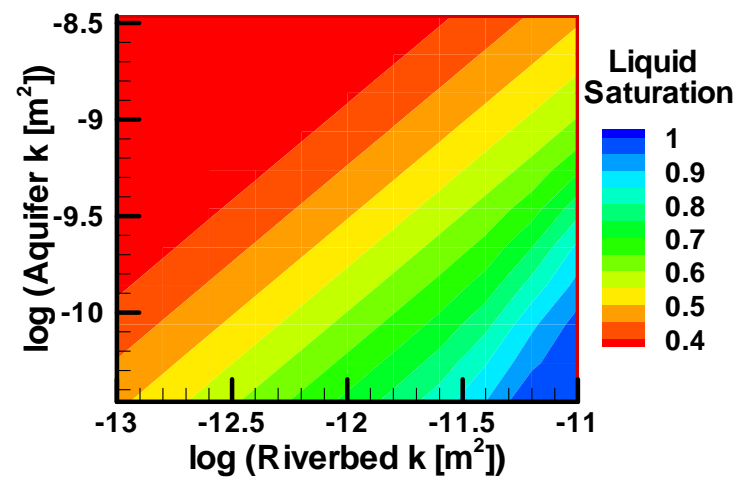

(b)

Figure 10 


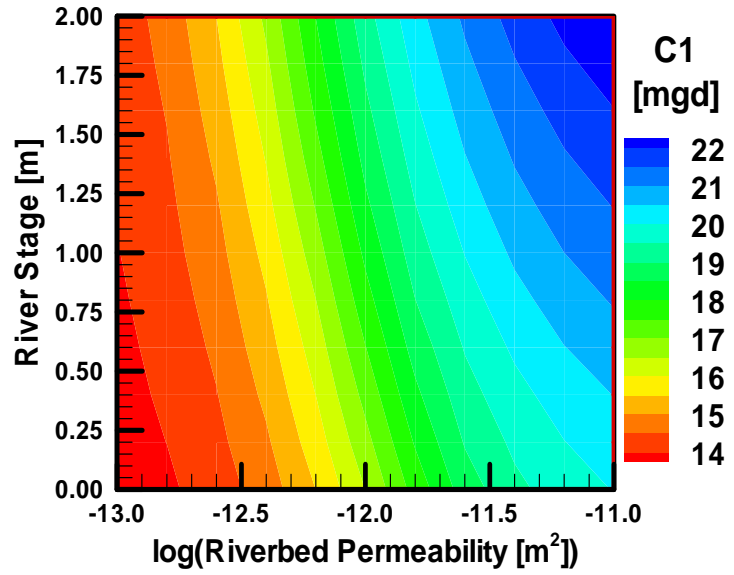

(a)

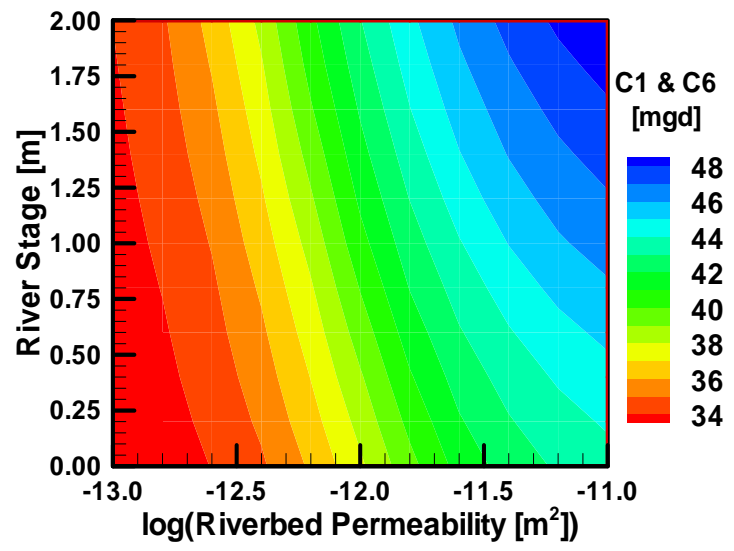

(c)

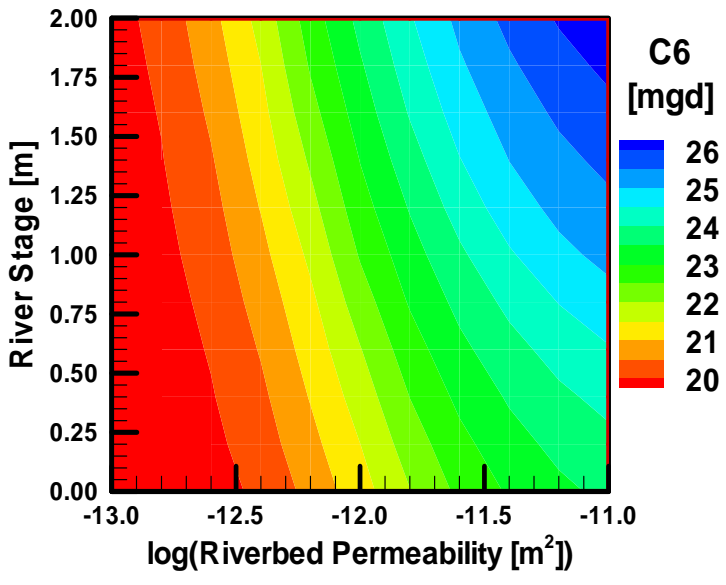

(b) 


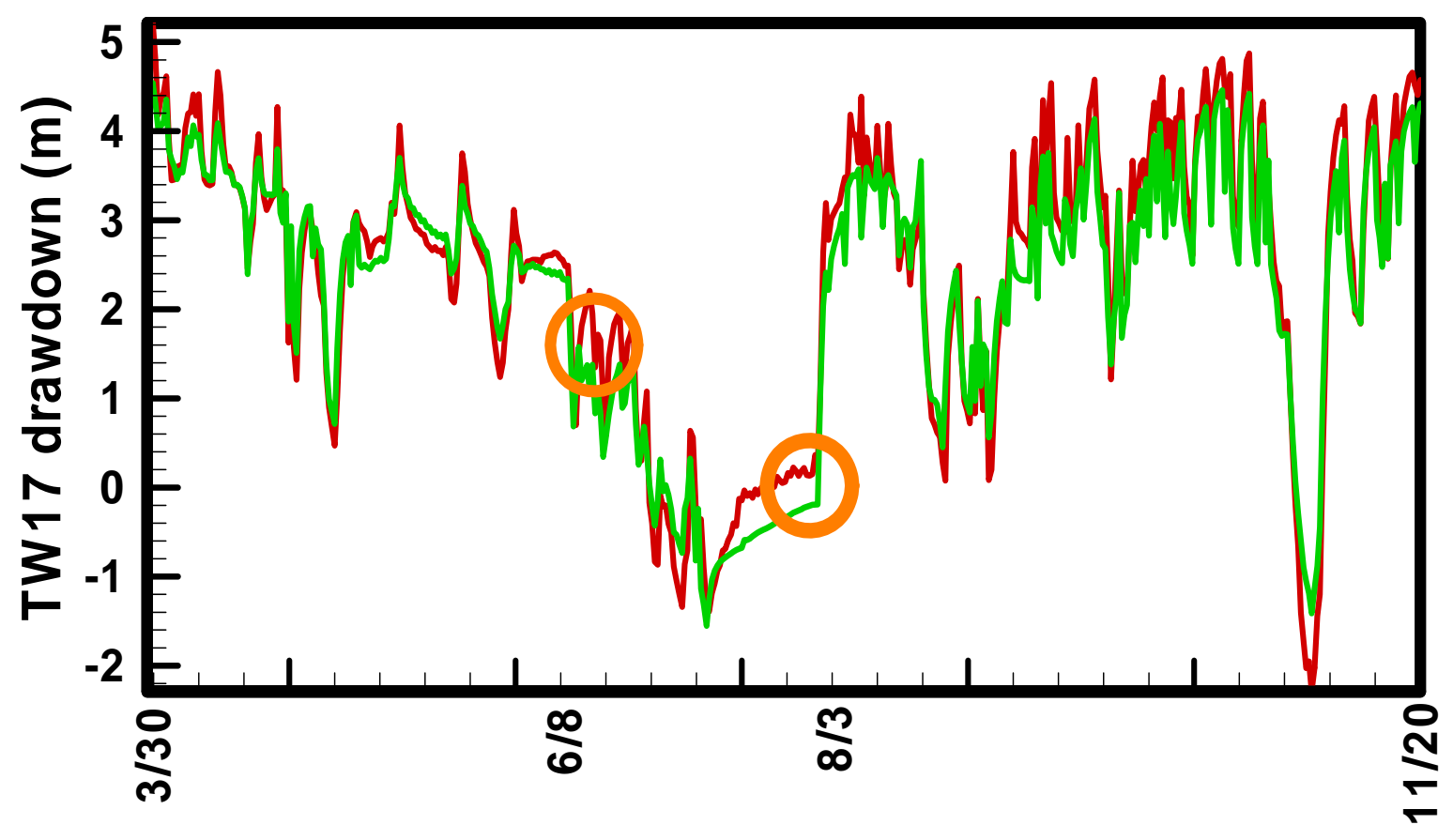

Figure 12 


\section{DISCLAIMER}

This document was prepared as an account of work sponsored by the United States Government. While this document is believed to contain correct information, neither the United States Government nor any agency thereof, nor The Regents of the University of California, nor any of their employees, makes any warranty, express or implied, or assumes any legal responsibility for the accuracy, completeness, or usefulness of any information, apparatus, product, or process disclosed, or represents that its use would not infringe privately owned rights. Reference herein to any specific commercial product, process, or service by its trade name, trademark, manufacturer, or otherwise, does not necessarily constitute or imply its endorsement, recommendation, or favoring by the United States Government or any agency thereof, or The Regents of the University of California. The views and opinions of authors expressed herein do not necessarily state or reflect those of the United States Government or any agency thereof or The Regents of the University of California.

Ernest Orlando Lawrence Berkeley National Laboratory is an equal opportunity employer. 